\title{
Acute Chest Syndrome
}

National Cancer Institute

\section{Source}

National Cancer Institute. Acute Chest Syndrome. NCI Thesaurus. Code C138179.

A vaso-occlusive crisis of the pulmonary vasculature occurring in patients with sickle cell disease. It is characterized by the presence of a new radiodensity on a chest radiograph accompanied by fever, cough, sputum production, dyspnea, or hypoxia. 